
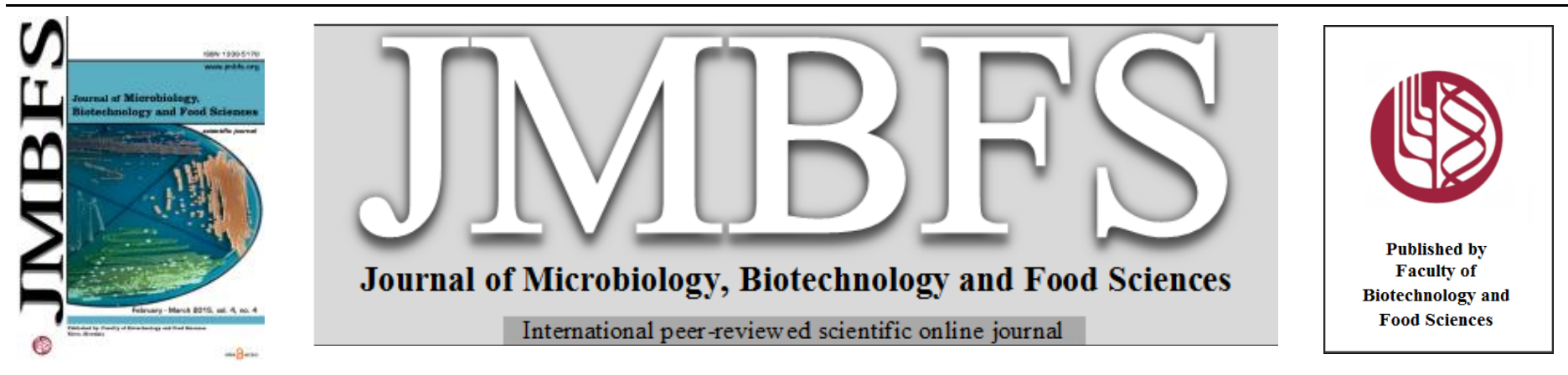

\title{
THE GLUCOSE EFFECT ON LINCOMYCIN PRODUCTION BY STREPTOMYCES LINCOLNENSIS VAR. LINCOLNENSIS DMS 40355 ON SYNTHETIC MEDIA
}

\author{
Kamila Majerčíková ${ }^{1}$, Roman Labuda ${ }^{2}$, Günter Jaunecker ${ }^{2}$, Soňa Javoreková ${ }^{{ }^{*}}$ \\ Address(es): \\ ${ }^{1}$ Department of Microbiology, Faculty of Biotechnology and Food Sciences, Slovak University of Agriculture, 94976 Nitra, Slovakia. \\ ${ }^{2}$ Romer Labs Division Holding GmbH, Technopark 1, 3430 Tulln, Austria.
}

*Corresponding author: sona.javorekova@uniag.sk

doi: 10.15414/jmbfs.2015.4.4.306-309

\section{ARTICLE INFO}

Received 25. 7. 2014

Revised 20.11. 2014

Accepted 28. 1. 2015

Published 1. 2. 2015

Regular article

OPEN $\partial_{\text {ACCESS }}$

\section{ABSTRACT}

The objective of this study was to obtain the information about the lincomycin production by type strain Streptomyces lincolnensis var. lincolnensis DSM 40355 on the synthetic medium. In order to improve the productivity, the ways of inoculation, effects of the medium components and fermentation time were investigated. The production of lincomycin was carried out at $30^{\circ} \mathrm{C}$ on rotary shakers at 180 rpm and was tracked on $3^{\text {rd }}, 7^{\text {th }}, 10^{\text {th }}, 12^{\text {th }}, 14^{\text {th }}$, and $16^{\text {th }}$ day of cultivation by using HPLC analysis. The results show that the highest production was observed on $16^{\text {th }}$ day of cultivation on production $\mathrm{M} 2$ medium at $30 \pm 1{ }^{\circ} \mathrm{C}$, after inoculation with $1 \mathrm{ml}$ of preculture M1 medium, and after an additional supplementation of the media with $0.5 \mathrm{~g}$ of glucose per $50 \mathrm{ml}$ medium on $7^{\text {th }}$ day of cultivation. Preculture medium application and glucose addition had positive effect, resulting in a remarkable increase in the lincomycin production.

Keywords: Antibiotics, lincomycin, actinomycetes, Streptomyces lincolnensis var. lincolnensis DMS 40 355, synthetic media

\section{INTRODUCTION}

Actinomycetes are important soil microorganisms. They can produce different kinds of secondary metabolites and are the main strains of producing biological active substances. Interestingly, the majority of the antibiotic-producing actinomycetes belong to the genus Streptomyces, which led to a growing economic importance for this group of organisms (Adegboye and Babalola, 2012).

Secondary metabolites production in microbes is strongly influenced by nutritional factors and growth conditions. It is necessary to optimize each and every component of fermentation media by varying the concentration of media constituents in order to achieve the maximum antibiotic production. The manipulation of growth conditions of microorganisms is a common strategy used by pharmaceutical companies to improve the quantities and spectra of secondary metabolites with potential therapeutic interest (Tormo et al., 2003). Scientific and rational optimization of fermentation process can not only greatly improve the levels of eventual products but also reduce the fermentation costs.

Actinomycetes fermentation is a complex of processes, it not only depends on the performance and fermentation medium, also requires the suitable environmental conditions (such as inoculation volume, medium capacity, fermentation time, temperature, agitation rate and initial $\mathrm{pH}$ ). These factors may affect the antibiotics production (Song $\boldsymbol{e t}$ al., 2012). The medium composition and ratio significantly affected fermentation process. Suitable nutrients can promote the synthesis of metabolites, cell growth, antibiotic fermentation unit, antibiotics extraction process, etc. (Kiers et al., 2000; Palmqvist and Hahn-Hagerdal, 2000).

Lincosamides form a small yet clinically important group of antibiotics Lincomycin, natural lincosamide antibiotic, was firstly reported and isolated in 1962 from a soil actinomycete found near Lincoln, Nebraska, which gave origin to its name (Stratton, 1998; Spížek et al., 2004). This new streptomycete species was designed as Streptomyces lincolnensis var. lincolnensis DMS 40355. As a lincosamide antimicrobial agent, lincomycin has gained clinical acceptance as a major antibiotics for the treatment of diseases caused by Gram-positive microbes, such as staphylococci and streptococci (Ye et al., 2009).

The first patent US3086912 A describing lincomycin production was registered by Bergy $\boldsymbol{e t}$ al. (1963). Several strains were obtained by extensive screening of different wild-type strains and appropriate patents were published (Spížek and Rezanka, 2004). Various chemicals were introduced to the fermentation to induce the formation of lincomycin-related antibiotics (Ye et al., 2009) and different experiments have been done to improve the yields of lincomycin.
Various vegetable oils, natural nitrogen sources, and surfactants were investigated for efficient lincomycin production from Streptomyces lincolnensis (Choi and Cho, 2004).

The aim of this study was to determine whether the glucose has effect on lincomycin production by type strain of Streptomyces lincolnensis var. lincolnensis DSM 40355 on the synthetic medium.

\section{MATERIALS AND METHODS}

\section{Production strain}

A type strain of Streptomyces lincolnensis var. lincolnensis DSM 40355 (DSMZ, Germany) was used in this study.

\section{Cultivation media and cultivation conditions}

Spore suspensions of $S$. lincolnensis var. lincolnensis DSM 40 355. were inoculated into preculture M1 medium adopted from Nechaeva et al. (1974) This medium contained (per 1): $1 \mathrm{~g} \mathrm{~K}_{2} \mathrm{HPO}_{4} ; 4 \mathrm{~g} \mathrm{NH}_{4} \mathrm{NO}_{3} ; 8 \mathrm{~g} \mathrm{CaCO}_{3} ; 0.05 \mathrm{~g}$ $\mathrm{MnSO}_{4} ; 0.02 \mathrm{~g} \mathrm{ZnSO}_{4} ; 0.05 \mathrm{~g} \mathrm{FeSO}_{4} ; 1 \mathrm{~g} \mathrm{MgSO}_{4} ; 8 \mathrm{~g}$ glucose. The precultures were conducted in $150 \mathrm{ml}$ Erlenmeyer flasks at $30{ }^{\circ} \mathrm{C}$ on rotary shakers at 180 $\mathrm{rpm}$ for $120 \mathrm{~h}$ and inoculated into the desired production medium. The production M2 medium (Wyss et al., 2001), synthetic minimal medium (carbon limited medium), used for lincomycin production contained (per 1): $3.12 \mathrm{~g} \mathrm{KNO}_{3}$; $750 \mathrm{mg} \mathrm{K} \mathrm{HPO}_{4} ; 750 \mathrm{mg} \mathrm{KH} \mathrm{PO}_{4} ; 500 \mathrm{mg} \mathrm{MgSO} \cdot 7 \mathrm{H}_{2} \mathrm{O} ; 100 \mathrm{mg} \mathrm{NaCl} ; 100 \mathrm{mg}$ $\mathrm{CaCl}_{2} \cdot 7 \mathrm{H}_{2} \mathrm{O} ; 0.396 \mathrm{mg} \mathrm{ZnSO}_{4} \cdot 7 \mathrm{H}_{2} \mathrm{O} ; 0.079 \mathrm{mg} \mathrm{CuSO} \cdot 5 \mathrm{H}_{2} \mathrm{O} ; 0.0405 \mathrm{mg}$ $\mathrm{MnSO}_{4} \cdot 7 \mathrm{H}_{2} \mathrm{O} ; 0.0175 \mathrm{mg} \mathrm{\textrm {MoO } _ { 3 }} ; 0.0375 \mathrm{mg} \mathrm{Na}_{2} \mathrm{~B}_{4} \mathrm{O}_{7} ; 0.5355 \mathrm{mg} \mathrm{FeSO}_{4} \cdot 7 \mathrm{H}_{2} \mathrm{O} ; 5$ g glucose. Production was carried out at $30{ }^{\circ} \mathrm{C}$ in $250 \mathrm{ml}$ Erlenmeyer flasks on rotary shakers at $180 \mathrm{rpm}$ on $3^{\text {rd }}, 7^{\text {th }}, 10^{\text {th }}, 12^{\text {th }}, 14^{\text {th }}$, and $16^{\text {th }}$ day.

\section{Inoculation experiments}

In the first case, $1 \mathrm{ml}$ of spore suspension of Streptomyces lincolnensis var lincolnensis DSM 40355 was used to inoculate $50 \mathrm{ml}$ of preculture medium with $1 \%$ of glucose. After $120 \mathrm{~h}$ of growth, $1 \mathrm{ml}$ of preculture medium was used to inoculate the production medium $(50 \mathrm{ml})$ with $2 \%$ of glucose. In the second case, $1 \mathrm{ml}$ of spore suspension of study strain $S$. lincolnensis var. lincolnensis DSM 40355 was inoculated directly into the $50 \mathrm{ml}$ of the production medium with $2 \%$ of glucose. 
Determination of pH and mycelia concentration (dry mycelia weight-DMW)

Values of $\mathrm{pH}$ were determined using a VARIO $\mathrm{pH}$ meter (WTW Wissenschaftlich-Technische Werkstätten GmbH, Germany). To measure the mycelia concentration in liquid medium after incubation, the cultures were autoclaved at $121{ }^{\circ} \mathrm{C}$ for $16 \mathrm{~min}$ to deactivate the actinomycete. DMW were obtained by harvesting the spores on pre-activated (at $80^{\circ} \mathrm{C}$ for $16 \mathrm{~h}$ ), and preweighed filter paper (Qualitative filter papers, Grade 1288; Sartorius Stedim Biotech). The filtered biomass (mycelia mass) was dried at $80{ }^{\circ} \mathrm{C}$ for $16 \mathrm{~h}$ and weighed again. The weight of the dried biomass was then determined as a difference between initial and final weight, and determined as dry weight.

\section{Quantitative determination of lincomycin production (HPLC conditions)}

Samples were analysed according to a method adopted by Douša et al. (2006) HPLC analysis was performed on a Gemini NX C18 column, $100 \mathrm{~mm}$ x $4.6 \mathrm{~mm}$, $3 \mu$ (Phenomenex), using an Ultimate 3000 HPLC-system (Dionex) with UV detection at a wavelength of $210 \mathrm{~nm}$. The mobile phase was constituted by solvent $\mathrm{A}, 2 \mathrm{mM}$ ammonium formate in water $(\mathrm{pH}$ was adjusted to 9 with ammonium hydroxide), and solvent $\mathrm{B}$, acetontrile. A linear gradient program was setup with $0-1.4 \mathrm{~min} 10 \% \mathrm{~B}, 1.4-5.4 \mathrm{~min} 10-30 \% \mathrm{~B}$, then hold at $30 \% \mathrm{~B}$ for 4 min before coming back to $10 \% \mathrm{~B}$ in $0.1 \mathrm{~min}$ (the HPLC column was reconditioned at $10 \% \mathrm{~B}$ for an additional $3 \mathrm{~min}$ ). The flow rate was $1.0 \mathrm{ml} . \mathrm{min}^{-1}$, and $20 \mu \mathrm{l}$ of the sample was injected onto the column. Data processing was carried out using Chromeleon software 6.8. Samples in a total amount of $1 \mathrm{ml}$ were taken at a particular sampling period $\left(3^{\text {rd }}, 7^{\text {th }}, 10^{\text {th }}, 12^{\text {th }}, 14^{\text {th }}\right.$, and $16^{\text {th }}$ day $)$ from a cultivation medium and centrifuged for 5 minutes at $13000 \mathrm{rpm}$ (Biofuge pico, Heraeus Instruments) in order to get cell free supernatant. The supernatan was then filtered through a filter (13 mm Syringe Filter w / $0.2 \mu \mathrm{m}$ PTFE, VWR International, USA), and $500 \mu \mathrm{l}$ of supernatant was directly used for HPLC analysis.

\section{Lincomycin production on M2 medium}

Based on the results obtained from HPLC analysis (a previous study and data not shown), the production of lincomycin on the M2 medium inoculated by $1 \mathrm{ml}$ of M1 medium (seed medium) resulted in better yields in production of lincomycin. In the second trail a glucose quantity was changed and consequently compared with the other fermentations. The production of lincomycin was monitored after single adding $0.5 \mathrm{~g}$ of glucose on $7^{\text {th }}$ day cultivation (feed batch). Cultures were cultivated under the fermentation conditions as stated above.

\section{RESULTS AND DISCUSSION}

In the present study, we report the lincomycin production by type strain Streptomyces lincolnensis var. lincolnensis DSM 40355 on synthetic (M2) medium. The affects of fermentation conditions for lincomycin production have been studied (Young et al., 1985; Li et al., 2007), but to our knowledge, this is the first report applying this synthetic medium for lincomycin production. The objective of this work was to compare the effects of spore suspension and preculture medium on the cell growth and antibiotic production and to investigate whether any improvement in lincomycin production could be achieved in fedbatch cultures compared with conventional batch fermentation. We proceeded from the fact that different antibiotics are formed under different conditions and


1960).

The results of HPLC analyses are presented in Table 1 . On the $3^{\text {rd }}$ day of cultivation, this metabolite was not produced on M2 medium inoculated with a spore suspension. On the $7^{\text {th }}$ day, the small amount of lincomycin was observed and during the next days, a hundred-fold increase in the production was achieved. A maximum production was reached on the $16^{\text {th }}$ day of cultivation, i.e. $6.828 \mu \mathrm{g} .1$

On the other hand, the lincomycin production on M2 medium, inoculated by the preculture medium (Table 1), was detected on the $3^{\text {rd }}$ day of cultivation, but further production of the antibiotic between $7^{\text {th }}$ and $14^{\text {th }}$ day was minimal. The precultures were able to increased lincomycin production, because the maximum concentration was $17.274 \mu \mathrm{g} . \mathrm{l}^{-1}$ on the last day of cultivation. The production was almost doubled after $14^{\text {th }}$ day of incubation when compared with that obtained on the $16^{\text {th }}$ day on M2 medium. The results of HPLC analysis show that M2 medium directly inoculated by spore suspension of the type strain of S. lincolnensis var. lincolnensis DSM 40355 produced about 2.5-fold lower amount of lincomycin.

Like mentioned Spížek, Rezanka (2004) pH value rose with declining glucose utilization. When carbon sources are exhausted, growth rapidly decreases, whereas lincomycin production remains constant for some time. In our results the decrease was only observed on M2 medium on the $3^{\text {rd }}$ day of cultivation. The optimum for biomass yield was different to that for antibiotic production and growth (DMW) of Streptomyces lincolnensis var. lincolnensis DSM 40355 Optimal values for growth of Streptomyces lincolnensis var. lincolnensis DSM 40355 were 7.09 in M2 medium and 5.23 in M1/M2 medium. The maximum values of the production of lincomycin were determined by us in $\mathrm{M} 2$ at $\mathrm{pH} 7.9$ and M1/M2 medium at $\mathrm{pH} 8.74$ during the late stages of growth. According to James et al. (1991) the optimum for biomass yield was different to that for antibiotic production and protease activity also exhibited some $\mathrm{pH}$ dependence. The protein secretion is not occurring through some cultural perturbation and may be linked to antibiotic production as an important element of secondary metabolism

Table 1 Effects of preculture medium application on lincomycin production by Streptomyces lincolnensis var. lincolnensis DSM 40355 at different time

\begin{tabular}{lcccccc}
\hline & \multicolumn{3}{c}{ M2 medium } & \multicolumn{3}{c}{ M1/M2 medium } \\
\cline { 2 - 7 } Time (days) & $\mathrm{pH}$ & $\begin{array}{c}\text { DMW } \\
\left(\mathrm{g} . \mathrm{l}^{-1}\right)\end{array}$ & $\begin{array}{c}\text { HPLC } \\
\left(\mu \mathrm{g} . \mathrm{l}^{-1}\right)\end{array}$ & $\mathrm{pH}$ & $\begin{array}{c}\text { DMW } \\
\left(\mathrm{g} . \mathrm{l}^{-1}\right)\end{array}$ & $\begin{array}{c}\text { HPLC } \\
\left(\mu \mathrm{g} . \mathrm{l}^{-1}\right)\end{array}$ \\
\hline 0 & $6.46 \pm 0.11$ & $0.11 \pm 0.01$ & - & $6.29 \pm 0.07$ & $0.28 \pm 0.01$ & - \\
3 & $6.72 \pm 0.30$ & $1.26 \pm 0.01$ & 0 & $5.23 \pm 0.10$ & $2.02 \pm 0.59$ & 700 \\
7 & $6.88 \pm 0.25$ & $2.32 \pm 0.20$ & 10 & $7.91 \pm 1.45$ & $1.91 \pm 0.16$ & 11039 \\
10 & $7.09 \pm 0.40$ & $3.35 \pm 0.38$ & 1200 & $7.88 \pm 1.31$ & $1.99 \pm 0.09$ & 11881 \\
12 & $7.24 \pm 0.37$ & $3.21 \pm 0.32$ & 4100 & $8.21 \pm 1.37$ & $1.96 \pm 0.01$ & 12100 \\
14 & $7.78 \pm 0.83$ & $2.72 \pm 0.45$ & 4600 & $8.57 \pm 0.98$ & $1.80 \pm 0.20$ & 13399 \\
16 & $7.90 \pm 0.89$ & $2.51 \pm 0.44$ & 6828 & $8.74 \pm 0.29$ & $1.78 \pm 0.12$ & 17274 \\
\hline
\end{tabular}

Legend: M1 medium (Nechaeva et al. 1974), M2 mineral medium with glucose and salt (Wyss et al. 2001), DMW - dry mycelia weight, HPLC - High-performance liquid chromatography.

Values reported for lincomycin concentrations are the averages of duplicate flasks.

Spížek and Řezanka (2004) indicated that under optimum conditions, the wildtype strain $S$. lincolnensis strain produced $25 \mathrm{mg} . \mathrm{l}^{-1}$ lincomycin A and negligible amounts of lincomycin B. In contrast, the strain $S$. lincolnensis 78-11 is a phageresistant, lincomycin-overproducing mutant of $S$. lincolnensis NRRL 2936 , synthesising about $2.5 \mathrm{~g} .1^{-1}$ lincomycin A.

The ability of streptomycete cultures to form antibiotics is not a fixed property but can be greatly increased or completely lost under different conditions of nutrition and cultivation (Waksman, 1961). Therefore, the medium constitution together with the metabolic capacity of the producing organism greatly affects antibiotic biosynthesis. Overproduction of secondary metabolites includes the physiological control, e.g. feed-back inhibition, carbon and energy source regulation, nitrogen source regulation, phosphate regulation and the effect of autoregulatory compounds. Changes in the nature and type of carbon, nitrogen or phosphate sources and trace elements have been reported to affect antibiotic biosynthesis in streptomycetes (Barratt and Oliver, 1994; Spížek and Tichý, 1995; Loun'es et al., 1996; Abbanat et al., 1999). According Spížek and Tichý (1995), Demain (1998) indicated that the regulatory mechanisms governing biosynthesis of secondary metabolites are extremely complicated.

Based on the results of HPLC analysis, the type strain Streptomyces lincolnensis var. lincolnensis DSM 40355 is able to produce lincomycin on the synthetic medium, and thus consequently, the second study was also carried out with this strain and the effect of glucose addition on the production of antibiotic was studied. As Young et al. (1985) pointed out that once growth is halted by 
depletion of one or more nutrients, the specific rate of lincomycin production falls rapidly. That was the reason for second fed-batch experiment, a total $0.5 \mathrm{~g}$ of glucose per $50 \mathrm{ml}$ (total per 1) was fed after 7 days of cultivation. An aim was to monitor the lincomycin production by using this way of fermentation (Figure $1,2)$.

Carbon sources such as corn starch, glucose, sucrose and molasses are commonly used as growth substrates to produce enzymes, antibiotics and other secondary metabolites by fermentation. At the beginning of the fifties Epps and Gale (1942) showed that the synthesis of enzymes of primary metabolism, mainly of catabolic ones, and growth are negatively affected by glucose. Magasanik (1961) called it "catabolite repression" (glucose effect) and assumed that the enzyme inhibition is induced by intermediates of a rapid catabolism of glucose.

The examples of Gram-positive bacteria subject to carbon catabolite regulation (CCR) are the actinomycetes. This group possessing a high GC content in DNA includes Streptomyces, a genus characterized by its ability to produce secondary metabolites. The synthesis of these compounds is usually sensitive to CCR. For example, glucose depresses the formation of many aminoglycoside antibiotics produced by actinomycetes (streptomycin, kanamycin, istamycin, neomycin) via repression of biosynthetic enzymes (Sanchez and Demain, 2002).

The results given in Figure 1 and 2 showed that glucose could play an important role in lincomycin production. Glucose addition has positive effect, resulting in a remarkable increase in the antibiotic production. A total yield of lincomycin on $10^{\text {th }}$ day was 1.7 -fold higher, and 1.9-fold higher compared with that of the first study. Choi and Cho (2004) found out that when olive oil was used as a sole carbon source, the lincomycin yield was about 2.0 -fold higher than that using a starch medium. In fact, lincomycin accumulation was increased by about $95 \%$ on M1/M2 medium in the cultivation run with the glucose additions, which sheds new lights on the strategy for improving the production of antibiotic from Streptomyces lincolnensis var. lincolnensis.

On the $12^{\text {th }}$ day, the lincomycin concentration was found to be higher than maximum amount obtained in the first study. The highest lincomycin titer (29.902 $\left.\mu \mathrm{g} . \mathrm{I}^{-1}\right)$ was observed on the synthetic M2 medium inoculated by preculture M1 medium on $16^{\text {th }}$ day of cultivation.

These observations suggest that in all those cases where preculture medium was used and glucose was added, yields of lincomycin were obtained earlier and were higher than those from the first run and those that did not apply further glucose addition. This can be improved by further optimization of fermentation process by a feeding strategy as well as the composition of additional supplements.

The results obtained in our study are not at variance with the research results described by Young et al. (1985), who find that the glucose additions did not appear to inhibit lincomycin production of Streptomyces lincolnensis in chemically defined media; in fact lincomycin accumulation was increased by about $20 \%$ in the run receiving the additions. Semenova et al. (1994) have reported that the batch-type feeding of carbohydrates resulted in an increase of the lincomycin yield by $23-24 \%$ compared to the un-fed mode.

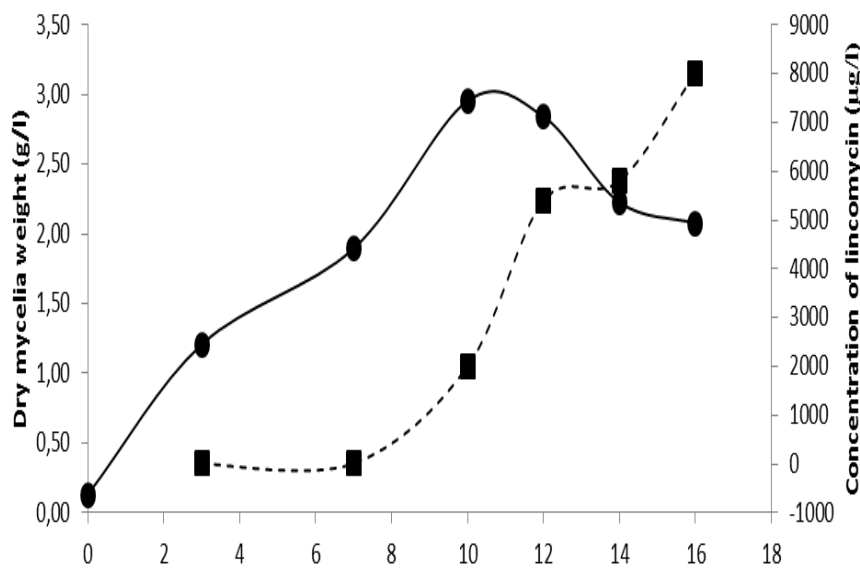

Period of incubation (days)



Period of incubation (days)

B

Figure 1 Comparison of mycelia concentration (dry mycelia weight) and lincomycin production during glucose fed batch fermentation of Streptomyces lincolnensis var. lincolnensis DSM 40355 on M2 medium (A) and M1/M2 medium (B). Starting medium composition was that of the standard fermentation. The fed batch received one glucose addition of $0.5 \mathrm{~g}$ on $7^{\text {th }}$ day of cultivation. Production was carried out at $30{ }^{\circ} \mathrm{C}$ in $250 \mathrm{~mL}$ Erlenmeyer flasks on rotary shaker at $180 \mathrm{rpm}$ on $3^{\text {rd }}, 7^{\text {th }}, 10^{\text {th }}, 12^{\text {th }}, 14^{\text {th }}$, and $16^{\text {th }}$ day of cultivation.

Legend: dry mycelia weight $(\mathrm{O})$; concentration of lincomycin $(\square \bullet)$. Reported data were the average of duplicate experiments.

The purpose of media optimization is to support the efficient growth of microorganisms. Different combinations of medium constituents and sequences of optimized fermentation conditions need to be investigated to determine the growth conditions, which produce the biomass with best suited physiological state constituted for antibiotic production (Nanjwade et al., 2010). A comparison of DMW results obtained in fed batch operation modes is depicted in Figure 1 and 2. The specific rate of lincomycin production is plotted as a function of biomass concentration also in Table 1. At the beginning the concentration of mycelia (dry weight) increased, that reached a maximum of $3.35 \pm 0.38 \mathrm{~g}^{-1} \mathrm{l}^{-1}$, but did not increase further and continued to decline during the phase of growing lincomycin concentration. These results indicate that DMW decreased with increasing antibiotic concentration similarly as in Young et al. (1985).

\section{CONCLUSION}

The highest production of lincomycin was detected on the M2 medium inoculated with a preculture M1 medium (seed medium), and after a single additional supplementation of the fermentation broth with $0.5 \mathrm{~g}$ of glucose/per 50 $\mathrm{ml}\left(10 \mathrm{~g} . \mathrm{l}^{-1}\right)$ on the $7^{\text {th }}$ day of cultivation. The $\mathrm{pH}$ during cultivation of Streptomyces lincolnensis var. lincolnensis DSM 40355 altered by the addition of glucose. Compared to the production of biomass, we observed the opposite development and raising the $\mathrm{pH}$ with increasing concentration of lincomycin in the medium. A widespread usage of the antibiotics, including lincomycin, may result in occurrence of pharmacologically active compounds in environment, and their traces can be consequently found in foods and/or feeds. Proper and accurate analytical method and mainly analytical calibrants (standards) are necessary for their reliable detection. Knowledge gained from this study will be used to produce fully ${ }^{13} \mathrm{C}$ isotope labeled lincomycin as internal standards (IS) for the accurate determination of this antibiotic in food and/or feeds by HPLC electrospray (ESI) MS/MS.

Acknowledgments: The research leading to these results has received funding from the European Community under project no 26220220180: Building Research Centre „AgroBioTech" and by the Ministry of Education by the Slovak Research Grant Agency from pro project No. VEGA 1/0476/13.

\section{REFERENCES}

ABBANAT, D., MAIESE, W., GREENSTEIN, M. 1999. Biosynthesis of the pyrroindomycins by Streptomyces rugosporus LL-42D005; Characterization of nutrient requirements. Journal of Antibiotics, 52, 117-126. http://dx.doi.org/10.7164/antibiotics.52.117

ADEGBOYE, M.F., BABALOLA, O.O. 2012. Taxonomy and ecology of antibiotic producing actinomycetes. African Journal of Agricultural Research, 7 , 2255-2261. http://dx.doi.org/10.5897/ajarx11.071

BARRATT, E.M. , OLIVER, S.G. 1994. The effects of nutrient limitation on the synthesis of stress proteins in Streptomyces lividans. Biotechnology Letters, 16, 1231-1234

BERGY, M.E., HERR, R.R., MASON, D.J. et al. 1963. Antibiotic lincolnensis and method of production. US Patent 3086912A, Upjohn Company. 
DEMAIN, A.L. 1998. Induction of microbial secondary metabolism. International Microbiology, 1, 259-264.

DOUŠA, M., SIKAČ, Z., HALAMA, M., LEMR, K. 2006. HPLC determination of lincomycin in premixes and feedstuffs with solid-phase extraction on HLB OASIS and LC-MS/MS confirmation. Journal of Pharmaceutical and Biomedical Analysis, 40, 981-986. http://dx.doi.org/10.1016/j.jpba.2005.07.041 EPPS, H.M.R., GALE, E.F. 1942. The influence of the presence of glucose during growth on the enzymic activities of Escherichia coli: comparison of the effect with that produced by fermentation acids. Biochemical Journal, 36, 619623.

CHOI, D., CHO, K. 2004. Effect of carbon source consumption rate on lincomycin production from Streptomyces lincolnensis. Journal of Microbiology and Biotechnology, 14, 532-539.

JAMES, P.D.A., EDWARDOS, C., DAWSON, M. 1991. The effects of temperature, $\mathrm{pH}$ and growth rate on secondary metabolism in Streptomyces thermoviolaceus grown in chemostat. Journal of General Microbiology, 137, 1715-1720.

KIERS, J.L., VAN LAEKEN, A.E.A., ROMBOUTS, F.M., NOUT, M.J.R. 2000 In vitro digestibility of Bacillus fermented soya bean. International Journal of Food Microbiology, 60, 163-169. http://dx.doi.org/10.1016/s0168 1605(00)00308-1

LI, X.B., ZHAO, G.R, ZHENG, H., YUAN, Y. 2007. Improved industrial fermentation of lincomycin by phosphorus feeding. Process Biochemistry, 42, 662-668. http://dx.doi.org/10.1016/j.procbio.2006.12.007

LOUN'ES, A., LEBRIHI, A., BENSLIMANCE, C., LEFEBVRE, G., GERMAIN, P. 1996. Regulation of spiramycin synthesis in Streptomyces ambofaciens effect of glucose and inorganic phosphate. Journal of Microbiology and Biotechnology, 45, 204-211. http://dx.doi.org/10.1007/s002530050671

MAGASANIK, B. 1961. Catabolite repression. Cold Spring Harbor Symposia on Quantitative Biology, 26, 249-256. http://dx.doi.org/10.1101/sqb.1961.026.01.031

NANJWADE, B.K., CHANDRASHEKHARA, S., GOUDANVAR, P.S., SHAMAREZ, A.M., MANVI, F.V. 2010. Production of Antibiotics from SoilIsolated Actinomycetes and Evaluation of their Antimicrobial Activities. Tropical Journal of Pharmaceutical Research, 9, 373-377. http://dx.doi.org/10.4314/tjpr.v9i4.58933

NECHAEVA, N.P., KOCHETKOVA, G.V., UKHOLINA， R.S. 1974

Lincomycin production on synthetic media. Antibiotiki, 19, 877-880.

PALMQVIST, E., HAHN-HAGERDAL, B. 2000. Fermentation of lignocellulosic hydrolysates II: inhibitors and mechanisms of inhibition. Bioresource Technology, 74, 25-33. http://dx.doi.org/10.1016/s09608524(99)00161-3

ŘEHÁČEK, Z., DOLEŽILOVÁ, L., VANĚK, Z. 1960. Antagonistic properties and mutual relationships of some actinomycetes. Folia Microbiologica, 5, 92-99. http://dx.doi.org/10.1007/bf02927473

SANCHEZ, S., DEMAIN, A.L. 2002. Metabolic regulation of fermentation processes. Enzyme and Microbial Technology 31, 895-906. http://dx.doi.org/10.1016/s0141-0229(02)00172-2

SEMENOVA, L.E., SHERSTOBITOVA, T.S., GOROKHOVA, I.B. 1994. The development of a technology for lincomycin biosynthesis with batch-type feeding the substrates during the process. Antibiot Khimioter, 39, 3-8.

SONG, Q., HUANG, Y., YANG, H. 2012. Optimization of fermentation

conditions for antibiotic production by actinomycetes YJ1 strain agains

Sclerotinia sclerotiorum. Journal of Agricultural Science, 4, 95-102.

http://dx.doi.org/10.5539/jas.v4n7p95

SPÍŽEK, J., NOVOTNÁ, J., ŘEZANKA, T. 2004. Lincosamides: Chemical Structure, Biosynthesis, Mechanism of Action, Resistance, and Applications. Advances Applied Microbiology, 56, 121-154. http://dx.doi.org/10.1016/s00652164(04)56004-5

SPÍŽEK J., ŘEZANKA, T. 2004. Lincomycin, cultivation of producing strains and biosynthesis. Applied Microbiology and Biotechnology, 63, 510-519. http://dx.doi.org/10.1007/s00253-003-1431-3

SPÍŽEK, J., TICHÝ, P. 1995. Some Aspects of Overproduction of Secondary

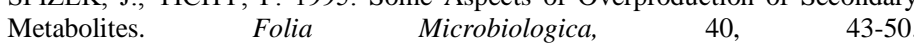
http://dx.doi.org/10.1007/bf02816527

STRATTON, C.W. 1998. Macrolides, lincosamides, and streptogramins: new agents and new roles. Antimicrobics and Infectious Diseases Newsletter, 17, 8995. http://dx.doi.org/10.1016/s1069-417x(00)88136-4

TORMO, J.R., GARCÍA, J.B., DEANTONIO, M., FELIZ, J., MIRA, A., DÍEZ, M.T., HERNÁNDEZ, P., PELÁEZ, F. 2003. A method for the selection of production media for actinomycete strains based on their metabolite HPLC profiles. Journal of Industrial Microbiology and Biotechnology, 30, 582-588. http://dx.doi.org/10.1007/s10295-003-0084-7

WAKSMAN, S.A. 1961. The actinomycetes. Williams and Wilkins Co, 363 p. WYSS, G.S., CHARUDATTAN, R., DeVALERIO, J.T. 2001. Evaluation of Agar and Grain Media for Mass Production of Conidia of Dactylaria higginsii. Plant Disease, 85, 1165-1170. http://dx.doi.org/10.1094/pdis.2001.85.11.1165

YE, R., WANG, Q., ZHOU, X. 2009. Lincomycin, rational selection of high producing strain and improved fermentation by amino acids supplementation.
Bioprocess and Biosystems Engineering, 32, 521-529. http://dx.doi.org/10.1007/s00449-008-0272-y

YOUNG, M.D., KEMPE, L.L,, BADER, F.G. 1985. Effects of phosphate, glucose and ammonium on cell growth and lincomycin production by Streptomyces lincolnensis in chemically defined media. Biotechnology and Bioengineering, 27, 327-333. http://dx.doi.org/10.1002/bit.260270318 